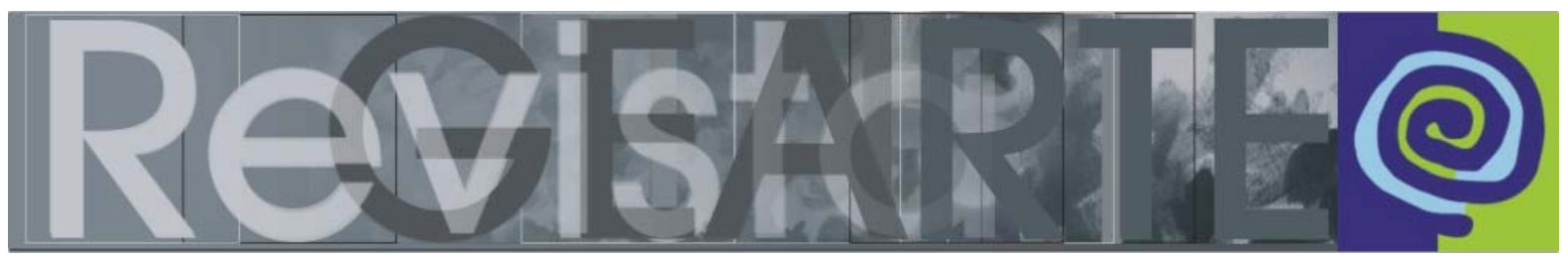

ISSN 2357-9854

\title{
Enredamentos entre leitura de imagens, produção de sentidos e politicidade
}

\author{
Sonia Tramujas Vasconcellos (UNESPAR - Brasil) \\ Tânia Maria Baibich (UFPR - Brasil)
}

\begin{abstract}
RESUMO
Discute-se a produção e a leitura de imagens nas aulas de Arte, envolvendo o visível e o dizível, a aparência e a opacidade, o que exige leitura de formas e de discursos. A ênfase é na articulação, na integração entre os códigos artísticos sistematizados historicamente e outros repertórios - pessoais, locais, da mídia - possibilitando a instauração de um ensinoaprendizagem diferenciado, com distintos modos de apropriação, de questionamento e de representação de conteúdos e de conhecimentos. Neste contexto discute-se a influência do modernismo na hierarquização e invisibilidade de determinados discursos artísticos, apontandose as consequências da pós-modernidade para a assunção de outros saberes e processos de leitura de imagens, oportunizando-se espaço e lugar a outros discursos e modos de análise, outras formas de enfrentamento e de aprendizagem, envolvendo experiências, narrativas, diálogos e escutas.
\end{abstract}

\section{PALAVRAS-CHAVE}

Leitura de imagens. Ensino de arte. Cultura visual. Modos de conhecer.

\section{ABSTRACT}

The product and reading images is discussed, involving the visible and the speakable, appearance and opacity, which requires reading of forms and of discourses. The emphasis is on articulation, on the integration between historically systematized artistic codes and other sources - personal, local, mediatic - enabling the establishment of a distinct teaching-learning process, with several methods of appropriation, of questioning and of representation of subjects and knowledge. Within this context, the role of arts based research is highlighted as it enables the inclusion of new modes of record and of performing artistic practices and the reading of images, more personal and interconnected with the imagetic and signifying universe of teachers and students. Such investigation methods exposes other discourses and methods of analysis, other forms of confronting and of learning, encompassing experiences, artistic and visual narratives, dialogues and listening.

\section{KEYWORDS}

Image reading. Art teaching. Visual culture. Knowing methods.

\section{Marcas da visualidade}

O olho da rua vê o que não vê o seu. Você, vendo os outros, pensa que sou eu? Ou tudo que teu olho vê você pensa que é você?

Paulo Leminski 
Diversas são as experiências e modos de leitura de imagens que realizamos cotidianamente, envolvendo percepções, pontos de vista, narrativas e distinções. Mas como vemos o que vemos? O que desse ver nos revela? 0 que priorizamos e o que é omitido nos exercícios de leitura? Cientes de que as imagens são aparatos simbólicos que difundem ideias, estilos de vida, valores e padrões de comportamento, evidenciando ou mascarando ideologias e hierarquias, o escopo desta escrita é partilhar questionamentos e possibilidades de exercícios do ver, envolvendo a produção e a leitura de artefatos imagéticos. Como consequência, se quer dar visibilidade e status de conhecimento ao que se faz nas aulas de artes visuais, desconstruindo binarismos e legitimando códigos de distintas e múltiplas identidades culturais.

No âmbito da educação em artes visuais, a visualidade - o modo como vemos o que vemos - deveria ser o principal objeto de estudo, visando transformações e aprofundamentos. Mas a cultura visual apresentada e discutida em sala de aula está alicerçada, em grande medida, em um hegemônico e canonizado discurso artístico, com escassez de discussões sobre a construção do gosto, o que envolve relações de poder e a consequente exclusão de diversas produções artísticas. Esse não é um discurso novo e se ampara nos debates sobre multiculturalismo, diversidade e alteridade cultural. Hoje, em uma era hipermoderna, a narrativa seletiva é confrontada com "o relevo, o sentido e a superfície social e econômica da cultura", pois essa se tornou mundo, "cultura-mundo", envolvendo a indústria cultural e seus discursos globalizantes, o consumismo, as mídias e as redes digitais (LIPOVETSKY; SERROY, 2011, p. 7). Nesse contexto, as discussões necessitam de outros aparatos, visto que a oposição binária e clássica entre cultura popular e erudita perde sentido, pois os diversos elementos da cultura são mercadoria de troca e a relação e ênfase em aspectos eruditos e populares se dá na construção de discursos legitimadores de ideias, conceitos e valores; na produção de visualidades que disseminam políticas e hierarquias.

No complexo e midiático espaço/tempo em que vivemos, os exercícios de produção e de leitura de imagens tem cada vez mais um papel de relevo, pois as imagens são, "entre outras coisas, também enigmas a serem deslindados em 
função da ampliação do entendimento dos contextos a que estão ligadas" (VICTORIO FILHO; CORREIA, 2013, p. 51), o que envolve a leitura e a indagação dos sentidos possíveis de sua construção, percebendo "elementos e efeitos de visualização ou de iconização que, embora sejam 'marginais', não são de modo algum inocentes" (MARIN apud SCHLICHTA, 2012, p. 957).

Deste modo, afirma Consuelo Schlichta (2012), a leitura de símbolos da cultura visual exige uma competência que não se dá naturalmente e que passa por um processo de educação dos sentidos, pois a interpretação não se restringe à análise das formas imagéticas, já que a representação não é propriamente figuração e sim "transfiguração", produto do ser humano historicamente condicionado, um universal "que surge no e pelo particular" (VÁSQUEZ, 2010, p. 25). Uma leitura de imagens que embebida em percepções singulares, contextuais e históricas não são unívocas, condicionadas a uma única interpretação. Para Jacques Rancière, a imagem artística nunca é uma realidade simples e direta e sim um "jogo de operações" relacionado a matrizes de cultura em que "formas visíveis propõem uma significação a ser compreendida ou a subtraem" (RANCIÈRE, 2012, p. 15). Nas distintas formas de partilha do sensível, "estas formas definem a maneira como obras ou performances 'fazem política', quaisquer que sejam as intenções que as regem" (RANCIÈRE, 2009, p. 17), embaralhando "as regras de correspondência" (2009, p. 20) e as relações entre o dizível e o visível. Esses posicionamentos adensam discussões e "cutucam" nossas percepções sobre a pensabilidade intrínseca na produção e leitura de imagens, envolvendo as relações entre visibilidade e visualidade, entre o que vemos e como lemos o que vemos.

\section{Leituras e sentidos das imagens}

As imagens se situam em um vastíssimo território. Abrimos os olhos e elas estão lá: na estampa das roupas, no rótulo dos produtos, nos outdoors, nos grafites urbanos, na televisão, no celular, na internet, nas capas de caderno, nas tatuagens. Imagens que são estéticas, informativas, decorativas, ideológicas. Imagens constitutivas de um espetáculo cultural, mas que ao permanecerem marginais e invisíveis no espaço escolar, e desgastadas na lógica do mercado, 
transformam "o desejo de saber em mera pulsão de ver" (MARTíN-BARBERO; REY, 2004, p. 17).

Retomo, deste modo, a decadência de um regime da visualidade que polariza as imagens entre as sublimes (as artísticas, da alta cultura) e as do entretenimento, pois ambas são "avatares culturais, políticos e narrativos" (MARTÍN-BARBERO; REY, 2004, p. 17) que requerem atenção, conscientização e crítica. E é nesse sentido que o ensino de arte necessita incorporar e discutir os efeitos sociais das imagens, da cultura visual, adensando seus significados e legitimações.

Os anos de 1980 merecem destaque na discussão sobre a imagem nas aulas de Arte ao se situar como um período em que o ensino de arte no Brasil é repensado em novas bases conceituais, e os professores passam a enfatizar não somente a expressão artística dos alunos, mas também a leitura de imagens e sua contextualização histórica (BARBOSA, 1996; PILLAR, 1999). Destaca-se o papel desempenhado por Ana Mae Barbosa na elaboração e disseminação da Abordagem Triangular no ensino das artes visuais, envolvendo a leitura de obras artísticas e imagens da cultura visual, sua contextualização (com o presente e o passado) e a produção artística dos estudantes.

A leitura de imagens é uma prática educativa intimamente relacionada ao ensino das artes visuais e Analice Dutra Pillar (1999, p. 12) a situa como um processo de compreensão de expressões formais e simbólicas para "atribuir significado seja a uma imagem, seja a um texto".

Ao ler, estamos entrelaçando informações do objeto, suas características formais, cromáticas, topológicas; e informações do leitor, seu conhecimento acerca do objeto, suas inferências, sua imaginação. Assim, a leitura depende do que está em frente e atrás dos nossos olhos. (PILLAR, 1999, p. 12)

Mas o foco no que está em frente e atrás da imagem enfatiza os conhecimentos visuais e as experiências anteriores dos alunos, procurando aproximar e ampliar repertórios. Mas algo fica de fora: a politicidade das imagens, retirando um dos objetivos principais da leitura e da produção artística em sala de aula, a percepção de posições heterogêneas no que se faz e no que 
se vê, de questionamento sobre a naturalização e a marginalização de manifestações e posicionamentos culturais. O que queremos chamar atenção é que o exercício de ver requer "um esforço de interpretação da produção artística para vê-la como expressão de alguém para outro alguém e como uma mensagem a ser compreendida" (SCHLICHTA, 2012, p. 959-960). Uma educação do olhar que necessita de conhecimento especializado, de aprofundamento de referências e de seus nexos na medida em que dialoga com a transparência da imagem (sua aparência) e a sua opacidade (a carga subjetiva, possuidora de realidades, de escolhas). Esta reflexão, apresentada por Fatorelli (2003) e Wolff (2005), destaca que a relação identitária da imagem com a aparência, com o seu referente, é a transparência; sendo sua complexidade, expressa em arranjos do visível e envolvendo jogos de poder, de hierarquização e naturalização, a opacidade.

É nesse viés que o ensino de arte transforma e amplia os sentidos necessários à leitura de manifestações culturais e imagéticas, transmutando o reconhecer em conhecer e instaurando o dialogismo (FATORELLI, 2003) como condição formativa da leitura. O argumento aqui defendido é que a especificidade e domínio profissional do professor de Arte requer uma articulação mais intrínseca entre cultura(s) e ensino de arte, educação e cotidiano, visualidades e teorias críticas, para que processos artísticos, construção de narrativas e alteração de saberes se incorporem de modo efetivo na prática e no modo como professor e estudantes apreendem e reelaboram o conhecimento dessa área de saber, realizando interpretações e depurações da cultural visual.

A cultura imagética é extensa, abrangendo a realizada pelos jovens, mas essa permanece um assunto controverso e evitado por vários professores de Arte da educação básica e do ensino superior, que optam por inserir em suas aulas "imagens consideradas como obras de arte que acompanharam e testemunharam, de uma forma ou de outra, os desdobramentos da trajetória humana" (VICTORIO FILHO; CORREIA, 2013, p. 50); imagens seletivas e consideradas relevantes no plano da cultura e, por isso, condicionadas, via de regra, à arte erudita. Adentrar e aprofundar visualidades, preconceitos, negações 
e acontecimentos que rondam o espaço escolar exigem rompimentos, ousadia, abertura ao outro. Para Aldo Victorio Filho e Marcos Correia (2013, p. 51), as imagens não são "a superfície dos contextos dos quais emergem, e sim, em muitos aspectos, o corpo do acontecimento".

Torna-se cada vez mais necessário e urgente que analisemos as nossas "velhas e persistentes crenças na existência de princípios universais no âmbito das artes visuais" (FRANZ, 2012, p. 236), pois todo o saber tem uma origem e é condicionado socialmente, sendo que a sua compreensão demanda a desconstrução de posturas epistemológicas locais e culturais, resultado de visões específicas (e sempre parciais) de mundo e de sociedade. A dificuldade e a relutância em falar e inserir referências que discutam racismo, intolerância, preconceito, entre tantas outras questões precisam ser superadas pelos professores (das escolas, das faculdades), porque esses "acontecimentos" estão presentes na arte, na mídia, no cotidiano e afetam a formação do aluno. "O etnocentrismo é uma dimensão implícita do racismo", assim como o egocentrismo e o eurocentrismo, do preconceito (CHALMERS, 2003, p. 50).

Queremos ressaltar que o acesso e contato das pessoas com acervos artísticos ampliam o conhecimento e propiciam leituras de códigos, de contextos, e precisam ser incentivados nos espaços formativos, nas aulas de Arte. A nossa luta é outra. O que evidenciamos e questionamos é a visão modernista de arte que seleciona e distingue o que merece status de arte, repercutindo nas práticas de ensino que inculcam signos e privilegiam determinados segmentos da cultura. A ausência de questionamentos sobre a seleção de determinados artistas e obras em acervos museológicos e compêndios de história da arte perpetua hierarquias e mantém invisível os discursos de outros grupos e tessituras sociais. Essa invisibilidade impede discussões e análise crítica de políticas e práticas culturais. Impede rupturas com as ilusões confortadoras que reduzem à arte ao que é belo, fruto de genialidade artística. A flexibilidade e sensibilidade à diversidade de visualidades é também uma forma de enfrentamento e de criação de outros modos de diálogo com a produção simbólica e com a diversidade sociocultural do mundo, do cotidiano e dos sujeitos escolares. Um ensino de arte no qual o acesso a códigos artísticos sistematizados historicamente se agrega 
com outros repertórios artísticos e culturais - e também pessoais, locais, da mídia - possibilita a instauração de uma educação dialógica, colaborativa e crítica, com variados modos de apropriação, de questionamento e de apropriação de conteúdos e de saberes.

\section{Dicotomias do saber, modernidade e invisibilidades}

Sejamos sinceros: é impossível abordar e discutir a extensa cultura visual produzida pela humanidade nos espaços formativos. Os discursos, leis e práticas vinculadas à educação - escolar e acadêmica - estão relacionados ao direito de acesso à herança cultural da humanidade e à promoção de um ensino intencional e sistematizado que transforme o conhecimento fragmentado e ingênuo em um conhecimento mais coerente e articulado. Mas para que isso ocorra é necessária uma seleção cultural dos conhecimentos a serem transmitidos frente ao limitado tempo de formação, o que envolve "uma dinâmica altamente conflituosa e que depende de todo o tipo de fatores sociais, políticos e ideológicos" (FORQUIN, 1992, p. 30). Entre os conflitos, situa-se a enorme perda de saberes da nossa herança cultural embutida nessa seleção, já que "os ensinos dispensados nas escolas não transmitem nunca senão uma ínfima parte da experiência humana acumulada ao longo do tempo" (FORQUIN, 1992, p. 29); conflitos que adentram as salas de aula apaziguados e supostamente resolvidos pelos intelectuais da área.

Para Boaventura Santos (2006), as discussões e atritos no campo das ciências evidenciam o conflito entre o paradigma da ciência moderna - de ordem hegemônica e ligada ao eurocentrismo - e o paradigma da pós-modernidade. Esse último relacionado à valorização de outras culturas, de distintas formas de saber e ao direito à existência dessas expressões. Um novo paradigma que se constrói em oposição à hegemonia de um saber-poder e que traz à tona uma modernidade que oculta a colonialidade ${ }^{1}$ do poder, "o lado obscuro e necessário da modernidade" (MIGNOLO, 2003, p. 30).

\footnotetext{
${ }^{1}$ Diversos autores consideram que não existe modernidade sem colonialidade, assim como não poderia haver uma economia-mundo capitalista sem as Américas (DUSSEL, 2000; QUIJANO, 2000).
} 
É nesse cenário que Santos questiona quais representações têm sido construídas e aceitas, e quais permanecem subjugadas, invisíveis em uma dicotomia que combinaria "a simetria com a hierarquia" (2006, p.; 781), pois a simetria entre as partes é sempre "uma relação horizontal que oculta uma relação vertical", como a dicotomia "conhecimento científico/conhecimento tradicional; homem/mulher; cultura/natureza; civilizado/primitivo; capital/trabalho; branco/negro; Norte/Sul; Ocidente/Oriente; e assim por diante" (SANTOS, 2006, p. 782).

Ao cruzarmos essas discussões com a leitura de certas imagens em sala de aula, destacamos a compreensão parcial e seletiva de mundo que essa ação promove. Marta Alexandre (2012, p. 31), baseada nas ideias de Boaventura Santos, esclarece que o pensamento moderno ocidental demarcou uma linha separando a realidade social em dois universos.

O universo daquilo que tem valor e que é visível e o universo daquilo que não tem valor e que é invisível. O universo do lado de cá da linha é tido como realidade, enquanto o universo do outro lado da linha é excluído e dado como inexistente.

Desse modo, a realidade social legitimada pelo sistema eurocêntrico, pelos compêndios enciclopédicos e de história da arte, estaria assentada sobre a dicotomia visível/invisível, assumindo como natural a exclusão de uma das partes, a invisível. Torna-se evidente que essa seleção, esse privilégio de determinados discursos, diminuiu ou subtraiu o mundo tanto quanto o expandiu ou adicionou de acordo com as suas próprias regras (SANTOS, 2006, p. 785). É nesse viés que Santos denuncia uma "contratação do presente", que esconde a riqueza e a diversidade das experiências sociais que acontecem no mundo.

Embasada nessas reflexões é que salientamos a relevância e o cuidado com os exercícios de produção e de leitura de imagens na escola, nos cursos de formação de professores de Arte, para que propiciem desnudamentos e ampliações de modos de análise e de perscrutamento do que se vê, se elabora e se acolhe no ensino de arte, fomentando novas visibilidades, entre transparências e opacidades. Práticas culturais que em um contexto educacional no qual os jovens escolares cada vez mais questionam o que e o modo como se 
ensina e se avalia, dão novo sentido e vigor aos exercícios de leitura e de produção de artefatos imagéticos. De outro lado, também fortalece o trabalho diferenciado do professor de artes visuais ao trazer para o primeiro plano a especificidade e a diversidade da linguagem visual, assim como uma relação mais intrínseca e visceral entre arte, ensino, diversidade, política e visualidades.

O alerta que fazemos após a defesa por um ensino de arte confrontador e crítico, é que o processo e a produção imagética ao serem utilizados para a externalização de sentimentos e pontos de vista, propiciando espaço e visibilidade para outros discursos, nem sempre aprofundam a análise dessas representações, que também são culturais e ideológicas. Ou seja, o incentivo a experiência e ao auscultamento de outras narrativas podem reduzir as tensões políticas do que se revela, se seleciona, reforçando um humanismo liberal no qual as diferenças e peculiaridades - da pessoa, de seu cotidiano, das relações entre arte e mídia, arte e cultura popular - são apresentadas na perspectiva do encantamento e do ufanismo pela singularidade e diversidade cultural. Esse é o cuidado, a vigília, para que a análise da experiência visual refute binarismos, aguce interpretações e leituras ampliadas de suas formas, sentidos e objetivos e se constitua parte fundamental e imbricada do processo de educação crítica de sujeitos.

\section{Referências}

ALEXANDRE, Marta Susana Filipe. Representação e legitimação do conhecimento científico e suas áreas de especialidade: análise crítica de entrevistas com cientistas portugueses. Lisboa, Portugal, 2012, 291 p. Tese (Doutorado em Letras) - Universidade de Lisboa, Faculdade de Letras, Área de Literaturas, Artes e Culturas, 2012.

BARBOSA, Ana Mae T. B. A imagem no ensino da arte: anos oitenta e novos tempos. 2 ed. São Paulo: Perspectiva, 1996.

BARBOSA, Ana Mae T. B. Apresentação. In: BARBOSA, Ana M. T. B; DA CUNHA, Fernanda Pereira (Orgs.). Abordagem triangular no ensino das artes e culturas visuais. São Paulo: Cortez, 2010. p. 9-24.

CHALMERS, Graeme. Arte, educación y diversidade cultural. Barcelona: Ediciones Paidós Ibérica, 2003.

DIAS, Belidson. A/r/tografia como metodologia e pedagogia em artes: uma introdução. In: DIAS, Belidson; IRWIN, Rita (Orgs.). Pesquisa educacional baseada em arte: a/r/tografia. Santa Maria: Ed. da UFSM, 2013, p. 21-26.

DUSSEL, Enrique. Europa, modernidad y eurocentrismo. In: LANDER, Edgardo (Coord.). La colonidad del saber: eurocentrismo y ciencias sociales, perspectivas latino-americanas. Buenos Aires: Clacso, 2000. p. 246-256. 
EISNER, Elliot; BARONE, Tom. Arts based Research. Los Angeles: Sage Publications, 2012.

ELLIOT, John. La investigación-acción en educación. 6 ed. Madrid: Ediciones Morata, 2010.

FATORELLI, Antonio. Fotografia e viagem: entre a natureza e o artifício. Rio de Janeiro: Relume Dumará, 2003.

FORQUIN, Jean Claude. Saberes escolares, imperativos didáticos e dinâmicas sociais. Teoria \& Educação, Porto Alegre, n. 5, p. 28-49, 1992.

FRANZ, Teresinha S. Arte, imagem e mediação cultural. In: NUNES, Ana Luiza R. (Org.). Artes visuais, leitura de imagens e escola. Ponta Grossa: Editora UEPG, 2012. p. 235-245.

HERNÁNDEZ, Fernando. La investigación basada en las artes: propuestas para repensar la investigación en educación. Educatio siglo XXI, n. 26, 85-118, 2008.

LEAVY, Patricia. Method meets art: Arts-Based Research Practice. New York: Guilford Press, 2009.

LIPOVETSKY, Gilles; SERROY, Jean. A cultura-mundo: resposta a uma sociedade desorientada. Tradução de Maria Lúcia Machado. São Paulo: Companhia das Letras, 2011.

MARQUES, Isabel; BRAZIL, Fabio. Arte em questões. São Paulo: Instituto Caleidos, 2012.

MARTÍN-BARBERO, Jesús; REY, Germán. Os exercícios do ver: hegemonia audiovisual e ficção televisiva. 2 ed. São Paulo: Editora Senac São Paulo, 2004.

MIGNOLO, Walter. Historias locales/disenos globales: colonidad, conocimientos subalternos y pensamiento fronterizo. Madrid: Akal, 2003.

PESSI, Maria Cristina Alves dos Santos. Illustro mago: professores de arte e seus universos de imagens. Tese (Doutorado em Artes) Programa de Pós-Graduação em Artes Visuais da Universidade de São Paulo, USP, 2008.

PILLAR, Analice D. Leitura e releitura. In: PILLAR, Analice D. (Org.). A educação do olhar no ensino das artes. Porto Alegre: Mediação, 1999. p. 9-21.

QUIJANO, Anibal. Colonialidad del poder y clasificación social. Journal of world-systems research, v. 11, n. 2, p. 342-386, 2000.

RAMALHO E OLIVEIRA, Sandra. Imagem também se lê. São Paulo: Edições Rosari, 2009.

RANCIÈRE, Jacques. A partilha do sensível: estética e política. 2 ed. São Paulo: EXO

experimental Org./ Editora 34, 2009.

RANCIÈRE, Jacques. O destino das imagens. Rio de Janeiro: Contraponto, 2012.

RICHTER, Ivone M. Interculturalidade e estética do cotidiano no ensino das artes visuais. Campinas, SP: Mercado de Letras, 2003.

ROLDÁN, Joaquin; MARÍN VIADEL, Ricardo. Metodologías artísticas de investigación en educación. Archidona: Ediciones Aljibe, 2012.

SALLES, Cecília A. Gesto Inacabado: processo de criação artística. 2 ed. São Paulo: FAPESP: Annablume, 2004.

SANTOS, Boaventura de Sousa (Org.). Conhecimento prudente para uma vida decente: um discurso sobre as ciências revisitado. 2 ed. São Paulo: Cortez, 2006.

SCHLICHTA, Consuelo Alcioni B. D. A formação do educador em arte: algumas reflexões sobre a escolha do conteúdo necessário e o como ensinar. In: ENCONTRO NACIONAL DA ANPAP, 21, 2012. Rio de Janeiro. Anais... ANPAP, 2012, p. 949-962.

SIEGESMUND, Richard. On the need for Arts-Based Research: a response to Parisier. Disponível em: http://art2investigacion-en.weebly.com/uploads/2/1/1/7/21177240/siegesmund_ richard_.pdf. Acesso em: 06 fev. de 2014.

SULLIVAN, Graeme. Art practice as research: inquiry in visual arts. 2 ed. Los Angeles: SAGE Publications, 2010. 
TELLES, João A. Pesquisa educacional com base nas artes: pensando a educação dos professores como experiência estética. Educação e Pesquisa, v. 32, n. 3, p. 509-530, 2006.

VÁZQUEZ, Adolfo Sánchez. Convite à estética. Rio de Janeiro: Civilização Brasileira, 1999.

VICTORIO FILHO, Aldo; CORREIA, Marcos B. F. Ponderações sobre aspectos metodológicos da investigação na cultura visual: seria possível metodologizar o enfrentamento elucidativo das imagens? In: MARTINS, Raimundo; TOURINHO, Irene (Orgs.). Processos \& práticas de pesquisa em cultura visual \& educação. Santa Maria: Ed. da UFSM, 2013. p. 49-60.

WOLFF, Francis. Por trás do espetáculo: o poder das imagens. In: NOVAES, Adauto (Org.). Muito além do espetáculo. São Paulo: Senac, 2005. p. 16-45.

\section{Sonia Tramujas Vasconcellos}

Professora da Universidade Estadual do Paraná/UNESPAR, campus Faculdade de Artes do Paraná, no Curso de Licenciatura em Artes Visuais e co-lider do Grupo de Pesquisa Arte, Educação e Formação Continuada da UNESPAR. Graduada em Educação Artística e Pintura, mestre e doutora em Educação pela Universidade Federal do Paraná com realização de doutorado sanduiche na Northern Illinois University (CAPES, 4412/13-3) de setembro de 2013 a junho de 2014 para aprofundamento de estudos sobre a pesquisa baseada em arte na educação.

E-mail: soniatvasconcellos@gmail.com

Currículo: http://lattes.cnpq/7124035497111005

\section{Tânia Maria Baibich}

Professora do Programa de Mestrado e Doutorado em Educação da Universidade Federal do Paraná/UFPR. Graduada em Psicologia pela Universidade Federal do Rio Grande do Sul/UFRGS, Mestre em Educação pela UFPR, Doutora em Psicologia Social pela Universidade de São Paulo/USP com pós-doutorado em Preconceito na Escola pela Michigan University e em Pedagogia do Ensino Superior pela Universidade do Vale do Rio dos Sinos/UNISINOS. Coordena o Grupo de Pesquisa sobre Saberes e Práticas no Ensino Superior e é membro do Grupo de Pesquisa Formação de Professores, Ensino e Avaliação, coordenado pela pesquisadora Maria Isabel Cunha. Representante da UFPR na Comissão de Assessoramento da Fundação Araucária para as áreas de Educação e Psicologia

E-mail: tbaibich@gmail.com

Currículo: http://lattes.cnpq.br/3080419876026842 